Retraction

\title{
Retraction: Stein, J.A. et al. The Effects of Acute Caffeine Supplementation on Performance in Trained CrossFit Athletes. Sports 2019, 7, 95
}

\author{
Jesse A. Stein *D, Melitza Ramirez and Katie M. Heinrich $\mathbb{D}$ \\ Department of Kinesiology, College of Health and Human Sciences, Kansas State University, Manhattan, \\ KS 66506, USA; melitzar@ksu.edu (M.R.); kmhphd@ksu.edu (K.M.H.) \\ * Correspondence: jastein@ksu.edu; Tel.: +1-218-469-1837
}

Received: 11 December 2019; Accepted: 6 February 2020; Published: 18 February 2020

All authors of the published article [1] have agreed to retract it based on the basis of a data entry error (Figure 1). After re-examination of our results for our published manuscript in Sports, we identified incorrectly entered data for six subjects on two variables. Specifically, the subjects who received caffeine during the first session and placebo during the second session (Session 1_Treatment = 2) were incorrectly recorded in the 'Reps_Placebo' and 'Reps_Caffeine' columns. Thus, the statistical results in our published manuscript were in inaccurate regarding caffeine's effect during CrossFit exercise. Upon correction and re-analysis, we found that rather than a significant effect of caffeine, there was a significant effect of time (i.e., a learning effect). The paper [1] will therefore be retracted. We apologize to the readers of Sports for any inconvenience caused.

\begin{tabular}{|c|c|c|c|c|c|}
\hline & $\mid \begin{array}{c}\text { Session1 } \\
8{ }_{-}^{\text {Treatme }} \\
\text { nt }\end{array}$ & $\&$ Reps_Cindy.1 & 8 Reps_Cindy.2 & 8 Reps_Placebo & $\&$ Reps_Caffeine \\
\hline 1 & 1 & 214.00 & 240.00 & 214.00 & 240.00 \\
\hline 2 & 1 & 581.00 & 611.00 & 581.00 & 611.00 \\
\hline 3 & 1 & 458.00 & 485.00 & 458.00 & 485.00 \\
\hline 4 & 1 & 431.00 & 456.00 & 431.00 & 456.00 \\
\hline 5 & 1 & 510.00 & 611.00 & 510.00 & 611.00 \\
\hline 6 & 1 & 460.00 & 458.00 & 460.00 & 458.00 \\
\hline 7 & 1 & 423.00 & 421.00 & 423.00 & 421.00 \\
\hline 8 & 2 & 339.00 & 300.00 & 339.00 & 300.00 \\
\hline 9 & 2 & 373.00 & 372.00 & 373.00 & 372.00 \\
\hline 10 & 2 & 512.10 & 467.00 & 512.10 & 467.00 \\
\hline 11 & 2 & 486.00 & 460.98 & 486.00 & 460.98 \\
\hline 12 & 2 & 473.00 & 374.00 & 473.00 & 374.00 \\
\hline 13 & 2 & 533.00 & 474.00 & 533.00 & 474.00 \\
\hline
\end{tabular}

Figure 1. Database for [1]. Each row represents a subject in our investigation. Session 1_Treatment represents the treatment order $(1=$ placebo then caffeine, 2 = caffeine then placebo). Reps_Cindy. 1 and Reps_Cindy.2 represent the total number of repetitions performed during session 1 and session 2, respectively. Reps_Placebo and Reps_Caffeine represent the total number of repetitions performed during the placebo and caffeine sessions, respectively. 


\section{Reference}

1. Stein, J.A.; Ramirez, M.; Heinrich, K.M. The Effects of Acute Caffeine Supplementation on Performance in Trained CrossFit Athletes. Sports 2019, 7, 95. [CrossRef] [PubMed] 